Service Failure and Recovery in a Strategic Airline Alliance Context: Interplay of Locus of Service Failure and Social Identity

\author{
Karin Weber, $\mathrm{PhD*}$ \\ Assistant Professor \\ School of Hotel and Tourism Management \\ Hong Kong Polytechnic University \\ Hung Hom, Kowloon \\ Hong Kong, SAR, China \\ Tel: + (852) 2766 4031; Fax: + (852) 23629362 \\ Email: hmkweber@polyu.edu.hk
}

\author{
Beverley Sparks, $\mathrm{PhD}$ \\ Professor \\ Griffith Business School \\ Griffith University, PMB 50, GCMC, 9726, QLD \\ Australia \\ Tel: +(61) 75552 8766; Fax: +(61) 755528978 \\ Email: B.Sparks@griffith.edu.au
}

Journal of Travel \& Tourism Marketing 2010

* Corresponding Author 


\title{
Service Failure and Recovery in a Strategic Airline Alliance Context: Interplay of Locus of Service Failure and Social Identity
}

\begin{abstract}
There has been a dramatic increase in the past decade in the number of strategic alliances and business networks. Yet, despite these trends in the business environment, the individual firm-customer dyad has remained the contextual focus of most services marketing research (Gittell, 2002). Using a scenario study, this research investigates the effects of service failures in a strategic airline alliance setting, with a particular focus on locus of service failure and strength of social identification, on three alliance entities - a consumer's home carrier, the alliance partner airline, and the alliance. Study findings suggest that consumers' evaluations are more stable (less extreme) when the home carrier causes the service failure. In contrast, when a lesser known entity (partner airline) causes the service failure, consumers are more willing to rate that entity harshly. Furthermore, compared to weak identifiers, strong identifiers were not only more positive in their evaluation of the home carrier but also in their evaluation of the alliance, pointing to a halo effect, whereby positive evaluations of the home carrier are transferred to the alliance. Implications of study results are discussed and directions for future research provided.
\end{abstract}

Keywords: Service Failure, Alliances, Locus of Causality, Social Identity 


\section{INTRODUCTION}

There has been a dramatic increase in the past decade in the number of formal strategic alliances, as well as more loosely structured business networks (Achrol \& Kotler, 1999; Evans, 2001; Preble, Reichel \& Hoffman, 2000; Prenkert \& Hallen, 2006). Vargo and Lusch (2004, p. 6), in their call for marketing's evolution to a services-dominant logic, stated that, "firms can have long-term viability only if they learn in conjunction with and are coordinated with other channel and network partners." Yet, despite these trends in the business environment, the individual firm-customer dyad has remained the contextual focus of much of the extant services marketing research (Gittell, 2002). The growth of strategic alliances is based on the promise of standardized, seamless or similar service delivery. Importantly, it is possible that consumer evaluations of one service experience within the network/alliance of firms may result in attributions being made about other members of that network/alliance. While this is positive if the service delivered is of a high standard, what happens if the service is below expectations and fails?

Given its inherent characteristics of intangibility and variability, tourism and hospitality services are subject to occasional service failures whereby customer expectations are not met. As negative evaluations by customers of service provider attempts at service recovery directly result in significant losses for tourism and hospitality firms (Sparks, 2001), increasing attention has been placed on the development of effective service recovery strategies by managers and frontline staff to restore customer satisfaction (e.g., Chan, Wan \& Sin, 2007; Karatepe, 2006). While early research in the field often focused on classifying service failures and recovery strategies (e.g., Bejou, Edvardsson \& Rakowski, 1996; Colenut \& Carville, 1994; Nicholich \& Sparks, 1996; Sundaram, Jurowski, \& Webster, 1997), and examining their impacts on customer satisfaction, word-of-mouth communication and behavioral intentions (e.g., Hoffman \& Chung, 1999; Matilla, 1999; McCullough, 2000; McDougall \& Levesque, 1998; 1999; Sparks \& Bradley, 1997; Sparks \& Callan, 1996), more recently, theories from other disciplines, such as justice and fairness theory from organizational research have been applied to extend the understanding of service failure and recovery (Bradley \& Sparks, 2009; Collie, Sparks, \& Bradley, 2000; Ha \& Jang, 2009, Kim, Kim \& Kim, 2009; Namkung \& Jang, 2009; Sparks, 2002; Sparks \& Fredline, 2007; Wang, Matilla \& Bartlett, 2009). Yet, the environment in which tourism and hospitality firms are operating in is constantly evolving. Thus, there is currently an increased focus on gaining insights into the impact of technology-related service failures/recoveries (e.g., Black \& Kelley, 2009; Mattila, Cho \& Ro, 2009) and service recovery strategies directed at a culturally diverse customer base (e.g., Becker, 2000; Lee, Khan \& Ko, 2008; Lee \& Sparks, 2007; Mattila, 
2000). Common to all research on service failure/recovery in the tourism and hospitality field, indeed any service setting, thus far is that it has been limited to investigating the effects of service failure/recovery on customer evaluations in situations in which one organization was the sole service provider. Consequently, current service failure/recovery research has ignored potential consumer responses in situations in which two or more service providers are closely linked in the provision of services to the customer by means of a strategic alliance.

In a single service provider setting, a service firm, primarily through its front-line employees has direct control over the quality of its service provision and relationship-building efforts with the customer. In contrast, in a strategic alliance or business network setting, a service provider relinquishes this direct control by encouraging its customers to use the services of an alliance partner (Weber, 2002). Thus, there are a number of complex issues service providers have to contend with if they are a member of a strategic alliance. This is especially the case in situations of sub-optimal service delivery. For example, if service providers jointly offer a service to a customer and a service failure occurs, to which provider does the customer attribute the service failure? Does the extent to which customers identify with one of the providers impact their evaluation or behavior? These questions take on critical importance in a situation in which one network/alliance member causes the service failure but another alliance member has to deal with that failure.

This paper presents a study that investigates the effect of a service failure that occurs with one alliance airline on evaluations of another member airline of the alliance and the overall airline alliance brand. It incorporates potential moderating variables, namely the locus of the service failure and the strength of organizational identification. In order to ground the study theoretically, attribution and social/organizational identification theories are drawn upon. The article is structured as follows: First, the characteristics of multiple as opposed to single service provider settings are outlined. Then, the conceptual background is presented by reviewing pertinent literature relating to attribution theory and social identity theory, followed by hypotheses that guide this research. Next, a scenario based research design is presented that investigates the effects of locus of service failure and strength of social identification on the evaluation of various alliance members, both for specific airlines within an alliance as well as for the broader alliance level. Finally, findings are discussed and directions for future research outlined. 


\section{Multiple Service Provider Settings}

Potential benefits of strong, long-term provider-customer relationships have been well documented in the literature (Morgan \& Hunt, 1994; Reichheld \& Sasser, 1990). However, service failures and repeated unsuccessful service recoveries inhibit a firm's ability to develop longterm relationships with its customers. As previously mentioned, in a strategic alliance, a service provider relinquishes this direct control by encouraging its customers to use the services of a partner (Weber, 2002). In order to ensure that a service firm's membership in a strategic alliance is beneficial to, rather than compromising of, its competitive position in the long-term, there is a need to understand the potential impacts of a service failure event by a partner firm.

The airline industry with a focus on global airline alliances such as Oneworld and Star Alliance forms the context of the current study for three reasons: 1 ) service failures, for example, overbooking, lost luggage, and rude flight attendants, are common in the airline industry (Bowen \& Headley, 2006), 2) code-share agreements among airline alliance partners, an integral part of global strategic airline alliances, are likely to affect consumers' evaluation of their preferred airline (home carrier), partner airlines, and the alliance overall, and 3) potential effects on consumers' perceptions of, and behavior towards, a particular airline resulting from the exposure to the services of an alliance partner - who still has to be regarded as a competitor despite membership in the same alliance - have thus far not been investigated.

Several studies have shown that business travelers rate alliance benefits as not particularly important, relative to other specific airline benefits such as reputation and safety, and that relatively few travelers who had a preferred airline knew its alliance affiliation (Goh \& Uncles, 2003; Weber, 2005). Nevertheless, especially in a service failure situation that involves two airlines that actively promote their membership in a global airline alliance, it is likely that consumers also make a judgment about the alliance, in terms of satisfaction and behavioral intentions. We argue that, when service is delivered by an alliance member, consumers may not only evaluate a service experience at the event level but also make further evaluations of other members in the alliance (partners) as well as the overall alliance brand. Thus, three levels of evaluation might occur: (1) an evaluation of the 'home carrier'; (2) an evaluation of a partner service provider 'partner airline'; and (3) an evaluation of the overall alliance brand (such as Oneworld or Star Alliance). 


\section{CONCEPTUAL BACKGROUND}

\section{Attribution Theory}

The key focus of attribution theory is individuals' assignment of causal inferences about events they experience and/or witness, and the consequent influence of these inferences on evaluations and behaviors. Weiner (1980; 1985a; 1985b) was instrumental in advancing a taxonomy of the many causes that might be inferred to explain events. He proposed that causes can be classified by three independent causal dimensions: locus, stability, and controllability. Of particular interest to this study is locus, that in the service failure context, refers to a customer's perception of the location or origin of the failure event, where the source either rests with the customer him/herself (internal locus) or with a factor other than the customer, such as the service provider, a third party, or the environment (external locus).

Attribution theory has provided significant insights into service failure experiences. In general, research findings indicate that the more consumers believe a service failure is due to the service provider (external locus), the more likely they are to 1) exhibit dissatisfaction (Chang, 2008), 2) voice complaints to the firm and warnings to others (Susskind, 2005), and 3) believe that they are owed an apology and/or refund (Kelley et al., 1993). However, prior research on attributions in service failure situations has focused primarily on service failures and recovery attempts of a single service provider only. Moreover, in research where attributions to a third party (e.g., airport personnel) were assessed (e.g., Boshoff \& Leong, 1998), there was no formal affiliation between the service provider and that third party that was promoted to customers, as is the case for global airline alliance partners.

In an airline alliance context, prior research has shown that consumers have no clear perceptions of the various characteristics of an alliance entity, whether it should have any role in service failure/recovery situations and if so, what that role should be (Weber, 2005). Yet, consumers have clear expectations in terms of service recovery following a service failure for a specific service provider, including airlines, that has a distinct brand identity and clearly identifiable staff (e.g., Kelley \& Davis, 1994; Sultan \& Simpson, 2000). Thus, it is reasonable to propose that consumers have more specific expectations in terms of service recovery following a service failure on individual alliance airlines with a clearly identifiable brand than on a more intangible alliance entity. 
According to prior research, consumers' attributions are also important during service recovery (Sparks \& Callan, 1996; Swanson \& Kelley, 2001). In an alliance context, an airline may have to deal with a service failure that was caused by one of its alliance partner airlines. In evaluating recovery outcomes, consumers identify potential causes of the outcome and each party's responsibilities for the failure resolution. Thus, as prior research confirms that failures attributed to a particular service provider result in negative consumer evaluations and behavior towards that provider (Kelley et al., 1993), it is expected that the airline that caused the service failure experiences the most negative consumer evaluations and behavior. Conversely, the alliance airline that deals with the service failure has an opportunity to implement a successful recovery and as noted by Swanson and Kelley (2001), an employee-based service recovery leads to favorable evaluations and word-of-mouth intentions. Thus, provided that the recovery is successful, higher evaluations of the airline that dealt with the service failure are expected compared to the airline that caused the service failure and the following hypothesis is forwarded:

$\mathrm{H}_{1}$ The airline that causes the service failure is likely to experience the most negative consumer evaluations and behavior, followed by the airline that deals with the service failure, and lastly the alliance.

\section{Social Identity Theory/Organizational Identification}

The extent to which a customer identifies with a particular service provider is also likely to influence his/her evaluation of, and behavior towards, that provider and other partners in the alliance following a service failure event. Yet, to date, very few consumer behavior studies have looked beyond individual characteristics and their influences on behavior to assess the impact of the social context on consumer responses. Social identity theory (Tajfel \& Turner, 1985), and the related social categorization theory (Hogg \& Abrams, 1988), in particular, have received little attention as potential frameworks for understanding why people are concerned about justice in service failure and recovery situations, and how they may form a basis of affiliation, distinct from commitment (Ahluwalia, Burnkrant \& Unnava, 2000) and loyalty based on repeat purchase due to inertia, convenience, price or individual affective commitment (Mattila, 2001).

Social identity is defined as "individuals' sense of self that goes beyond their personal identity by developing a social identity” (Tajfel \& Turner, 1985, p. 8). Individuals do so by identifying with or categorizing themselves in a contextual manner as members of various social categories, for example, gender, ethnicity, occupation, sports teams as well as other, more shortlived and transient groups (Kramer, 1991). Organizational identification is regarded as a specific 
form of social identification whereby an individual defines him/herself in terms of membership of a particular organization (Bhattacharya, Rao, \& Glynn, 1995; Ferreira, 1996). Much of the research to date has focused on employees' relationships with their employer (e.g., Dutton, Dukerich, \& Harquail , 1994) and members' relationships with non-profit organizations, such as museums, theatres, and universities (e.g., Bhattacharya et al., 1995; Mael \& Ashforth, 1992). Yet, according to social identity theory people seek out organizations for identification purposes even when they are not formal organizational members (Scott \& Lane, 2000). Bhattacharya and Sen (2003, p. 77), in particular, argued that "in today's era of unprecedented corporate influence and consumerism, certain companies represent and offer attractive, meaningful social identities to consumers that help them satisfy important self-definitional needs. As a result, such companies constitute valid targets for identification among relevant consumers, even though they are not formal organizational members.” Airlines in Asia-Pacific, renowned for their high standards of operation and innovation, and consequent reputation (e.g., Skytrax, 2009; Wirtz \& Johnston, 2003) are likely to constitute such targets for identification among frequent flyers.

For social identification to occur a customer identifies with the characteristics of a particular brand, for example, the reputation an airline has gained, its leadership, innovations, and standards of excellence, and on that basis identifies with others, in the same social group, who also value the same brand. By associating with this airline and others who have a similar affiliation based on social identification with that airline, the customer derives a sense of pride, whether he/she is by him/herself or communicating with friends or relatives. On the basis of these positive feelings resulting from the association with the airline and the broader social group, s/he develops a social identification with the brand. This type of affiliation with a brand is fundamentally different from the loyalty construct prevalent in the marketing field, given the primary focus on sociological aspects of group behavior by the former compared to the focus on psychological and behavioral aspects of the consumer for the latter (e.g., van Knippenberg \& van Schie, 2000; Mael \& Ashforth, 1992). One of the most widely used measures for organizational identity is that of Mael \& Ashforth (1992) who proposed and tested it in the context of alumni's identification with their alma mater. Utilizing a Likert scale (strongly agree/disagree), individual scale items include the following: 1 When someone criticizes (name of target entity), it feels like a personal insult. 2 I am very interested in what others think about (name of target entity). 3 When someone praises this target entity, it feels like a personal compliment. 4. This target entity's successes are my successes. 
Recently, Haslam, Branscombe, and Bachmann (2003) examined how organizational identification affects consumer evaluations in a service failure situation. They found that consumers who identify strongly with a service provider appear to be more forgiving towards that provider in a service failure event than consumers who do not identify, especially in terms of repeat purchase intentions. While Haslam and his colleagues' research shed light on the impact of social identity in a service failure event, it does so in a single provider context only. Although not based on social identity theory, but rather the positivity/negativity effect, the work by Folkes and Patrick (2003) provides some insight into the evaluation of multiple entities when pre-existing positive expectations exist. Their research confirmed that for services, positive information about an employee led to positive inferences about other employees in the firm, and the firm itself. Choi and Mattila (2008) found customers who held pre-existing high expectations about the service firm tended to more satisfied following a service failure than those who held pre-existing low service expectations. Thus, in a similar manner it could be expected that those consumers who identify strongly with an organization will be more positive in their evaluations of that entity.

Based upon social identity theory and research on the positivity/negativity effect, the following hypotheses are advanced:

$\mathrm{H}_{2.1}$ Following a service failure, consumers who identify strongly with their home carrier will be more positive in their evaluations of, and behavior towards, this airline than consumers who do not identify with the home carrier.

$\mathrm{H}_{2.2}$ Following a service failure consumers who identify strongly with their home carrier will be more positive in their evaluations of, and behavior towards, this airline than of the partner airline and the alliance, whereas there will be little /no difference in the evaluation of the three entities for consumers who do not identify with the home carrier.

\section{METHOD}

A 2 (Locus of Service Failure: home carrier versus partner airline) x 2 (Social Identification: strong versus weak) x 3 (Entity: home carrier, partner airline, alliance) mixed MANOVA, with entity as the within-subject variable, examined satisfaction and behavioral intention ratings for each entity. This design involved the development of four scenario scripts. Participants were assigned to one of four conditions, each represented by a different scenario, and rated each of the three entities represented in the alliance (home carrier, partner airline, alliance). Dependent variables were satisfaction and behavioral intentions in relation to all three entities. 


\section{Sample}

Our research sought to obtain responses from a targeted group of community members those familiar with air travel. Therefore, rather than rely on a convenient sample of students, which much of this type of research tends to do (e.g., Cranage \& Sujan, 2004; McCullough, 2000) a sample of frequent business travelers residing in Australia was randomly drawn from an email list purchased from a professional list broker in Australia. The scenario-based questionnaire was designed for distribution via the Internet with assignment to treatments on a random basis. Completion time averaged 15 minutes. A draw for one of five US\$ 100 book vouchers (online store) together with the offer of a summary of the study findings served as an incentive for participation in and completion of the experiment. Our research aimed to test a set of hypotheses (rather than to generalize findings to a wider population), with the intent to have a minimum of 50 respondents for each of the four treatment conditions to satisfy the requirements for further analysis and testing of hypotheses (e.g., Patzer, 1996; Sawyer \& Ball, 1981). A total of 373 responses were obtained, for a response rate of $6.3 \%$. Following elimination of incomplete questionnaires, the final sample size was 313, not only meeting but exceeding the minimum requirement set for respondents in each treatment condition. Obtaining 313 respondents across the four treatment conditions resulted in unequal cell sizes, and thus, an unbalanced design. Given the potential effects on data analysis, several solutions have been proposed for the analysis of unbalanced designs, including randomly dropping selected data points from larger cells, or imputing cell means as additional data points into the smaller cells ( Little \& Rubin, 1987, Searle, 1987). Yet, Iacobucci (1995) notes that these historical solutions are suboptimal and discusses potential solutions included in statistical software packages such as SPPS which were adopted in this study. The GLM Repeated Measures procedure in SPSS provides both univariate and multivariate analyses for the repeated measures data, and both balanced and unbalanced models can be tested.

The majority of respondents were male (53\%), consistent with the wider population of frequent flyers (Whyte, 2002). About one quarter of the respondents was in the 46-55 years age group, followed by about 20\% of respondents each in the 36-45 years and 56 years and above age groups. The majority of respondents (70\%) had a preferred 'home' carrier and was enrolled in at least one frequent flyer program (61\%). Given respondents' familiarity with the study setting, the sample was deemed suitable for this study. 


\section{Stimulus Material}

Respondents were presented with a brief script designed to invoke either a strong or weak identification with the home carrier. Following this social identity manipulation, a service failure/recovery script was presented. This script was developed after perusal of service failure events detailed in airline-related publications and reviews of airline surveys. The scenario depicted a service failure event that involved two alliance partner airlines (home carrier and partner airline), and the alliance brand, on a code-shared flight. The service failure event related to a breakdown of the computer system of the airline that operated the flight, resulting in flight delays and the cancellation of a previously confirmed flight. The four scenarios were identical except for manipulations of the two independent variables. The scenario was extensively pretested to ensure that 1) the service failure/recovery scenario was believable and easily understood, given the complexities of the alliance setting, and 2) manipulations of the two independent variables performed as intended.

\section{Measurements}

Independent Variables

Locus of service failure and social identity represented the two independent variables. The locus of service failure was manipulated at two levels. In the 'Locus of Service Failure Home Carrier' condition, the home carrier caused the service failure; the partner airline had to implement the service recovery. Conversely, in the 'Locus of Service Failure - Partner Airline' condition, the service failure was caused by the partner airline while the home carrier had to implement the service recovery.

Strength of identification with the home carrier was also manipulated at two levels. In the strong identification condition, the script included material to strengthen identification with the home carrier, consistent with previous research (Bhattacharya et al., 1995; Mael \& Ashforth, 1992). In the weak identification condition no reference was made to any one carrier but rather a number of different carriers represented acceptable choices for the respondents (see Appendix 'A' for the scenario script).

\section{Dependent Variables}

There were two dependent variables. Overall satisfaction and behavioral intentions, incorporating word-of-mouth and repeat purchase intentions, for each of the three entities (home carrier, partner airline, and the alliance brand) were measured on multi-item scales. The measurement scales were operationalized and adapted from previous studies in marketing and 
social psychology, in particular from customer satisfaction and service encounter literature (Bitner \& Hubbert, 1994; Westbrock \& Oliver, 1991; Zeithaml, et al., 1996). Both the satisfaction and behavioral intention items were measured on a 7-point Likert scale.

\section{RESULTS}

\section{Scale Reliabilities}

Summated scales were formed for two measures: satisfaction and behavioral intentions. Prior to calculating reliability coefficients, items were reverse-coded where required. Cronbach alpha for satisfaction with the home carrier (HC), the partner airline (PA), and the alliance (A) $\left(\alpha_{\mathrm{HC}}=.87 ; \alpha_{\mathrm{PA}}=.89 ; \alpha_{\mathrm{A}}=.86\right)$ were computed and each was satisfactory, based on established benchmarks (Nunnally, 1978). For the behavioral intention scale, an improvement in internal consistency could be achieved with the deletion of one word-of-mouth item for the home carrier and the alliance $\left(\alpha_{\mathrm{HC}}=.91 ; \alpha_{\mathrm{A}}=.85\right)$, while for the behavioral intention scale for the partner airline all four items were retained $\left(\alpha_{\mathrm{PA}}=.89\right)$.

\section{Realism and Manipulation Checks}

Study participants were asked to respond to scenario scripts by imagining themselves in the role of the customer. Therefore, several measures assessing the realism of the provided scenarios were included (Wilson \& McNamara, 1982). Respondents found both the service problem and its handling realistic, and that they could adopt the role of the customer $(\bar{x}=5.68$; 5.50, 5.73, respectively, on a 7-point scale). Realism checks conducted for each of the four scenarios confirmed the results of realism checks at the aggregate level. Checks also confirmed that the manipulations for the two independent variables - locus of service failure and social identity were successful. The effectiveness of the 'Locus of Service Failure' manipulation was ascertained with two questions. Respondents in the respective conditions showed a high level of agreement that the service failure was caused by the airline that was supposed to have caused the service failure (with a corresponding low level of agreement of the airline being at fault that dealt with the service failure) [Service Failure (SF) caused by Home Carrier (HC) - SF caused by HC $\bar{x}=5.95$, SF caused by Partner Airline $\bar{x}=2.63, \mathrm{t}=9.12, \mathrm{p}<.001$; Service Failure caused by Partner Airline (PA) - SF caused by PA $\bar{x}=5.54$, SF caused by HC $\bar{x}=2.04, \mathrm{t}=11.48, \mathrm{p}<.001]$.

Mael and Ashforth's (1992) organizational identity scale was adapted to the study context being concerned with airlines to assess the effectiveness of the social identity manipulation. Respondents in the strong social identity condition had statistically significant higher ratings for each of the items than respondents in the weak social identity condition [Strong/Weak Social 
Identity - SI1 $\bar{x}=6.32 / 2.97, \mathrm{t}=15.57, \mathrm{p}<.001 ;$ SI2 $\bar{x}=6.13 / 2.93, \mathrm{t}=13.65, \mathrm{p}<.001 ;$ SI3 $\bar{x}$ $=5.81 / 2.41 \mathrm{t}=10.36, \mathrm{p}<.001 ;$ SI $4 \bar{x}=6.13 / 2.77, \mathrm{t}=15.54, \mathrm{p}<.001]$.

\section{Consumer Evaluations and Behavior}

A 2 (Locus of Service Failure: home carrier vs partner carrier) x 2 (Social Identification: strong vs weak) x 3 (Entity: home carrier, partner carrier, alliance brand) mixed MANOVA, with entity as the within subject variable, examined satisfaction and behavioral intention ratings for each entity. Significant multivariate and univariate results are shown in Table 1.

\section{Insert Table 1 about here}

\section{Locus of Service Failure}

Hypothesis 1 posited that the airline that causes the service failure is likely to receive the most negative consumer satisfaction evaluations and negative behavioral intentions, followed by the airline that deals with the service failure, and lastly the alliance. As expected, there was a significant locus of service failure $\mathrm{x}$ entity interaction effect $(F(4,256)=12.33, p<.001$, partial $\left.\eta^{2}=.161\right)$. Univariate results showed a significant effect on both variables. The interaction effects are graphically displayed for both the satisfaction and behavioral intentions variable in Figures 1 and 2 respectively.

\section{Insert Figures 1 \& 2 about here}

To break down the interaction, contrasts were performed comparing each entity at the different levels of locus of causality. When the service failure was caused by the partner airline, contrasts revealed that customers perceived the partner airline statistically significantly lower in terms of satisfaction and behavioral intentions than the home carrier and the alliance $(p<.001)$. In addition, the difference between the home carrier and the alliance was significant at $\mathrm{p}<.001$ level for satisfaction, and significant at the $\mathrm{p}<.05$ level for behavioral intentions. When the service failure was caused by the home carrier, behavioral intentions varied statistically for the entities under investigation but satisfaction levels did not. Contrasts revealed that the home carrier and the alliance were rated statistically significantly higher for behavioral intentions $(p<$ .001) compared to the partner airline. There was no significant difference in ratings between the home carrier and the alliance. 
Simple effects tests undertaken within each entity level revealed that the partner airline was evaluated quite differently depending on the locus of causality. Respondents gave the partner airline significantly higher ratings if the home carrier had caused the service failure than if the partner airline had caused the service failure for both satisfaction and behavioral intentions. There was no significant difference at the .05 level by cause of the service failure when either the home carrier or the alliance was evaluated on either dependent variable.

In general, an inspection of the graphs (Figures 1 \& 2) suggests that consumers' evaluations are more stable (less extreme) when the home carrier causes the service failure. In contrast, when a lesser known entity (partner airline) causes the service failure, consumers are more willing to rate that entity harshly. In summary, Hypothesis 1 received partial support only in that the airline that caused the service failure experienced the most negative consumer evaluations and behavior, followed by the airline that dealt with the service failure, and lastly the alliance however, that was the case only when the partner airline caused the service failure. Hypothesis 1 was rejected when the home carrier caused the service failure as it still experienced higher satisfaction and behavioral intention ratings than either the partner airline or the alliance.

\section{Social Identity}

Hypothesis 2.1 posited that consumers who identify strongly with their home carrier will be more positive in their evaluations of, and behavior towards, this airline following a service failure than consumers who do not identify with the home carrier. Results indicated that there was a significant overall multivariate between-subject main effect for Social Identity $(F(2,258)=$ 14.39, $p<.001$, partial $\eta^{2}=.100$ ). Univariate results showed a significant effect for satisfaction and behavioral intentions. An inspection of the mean scores indicated that respondents who strongly identified with the home carrier were significantly more satisfied and had significantly more favorable behavioral intentions than respondents who weakly identified with the home carrier.

Hypothesis 2.2 posited that following a service failure consumers who identify strongly with their home carrier will be more positive in their evaluations of, and behavior towards, this airline than of the partner airline and the alliance, whereas there will be little/no difference in the evaluation of the three entities for consumers who do not identify with the home carrier. There was a significant overall multivariate interaction effect for social identity and entity $(F(4,256)=$ 8.66, $p<.001$, partial $\eta^{2}=.119$ ). Univariate results showed a significant effect on both satisfaction and behavioral intentions. The interaction effect is graphically displayed in Figure 3 
for satisfaction, with the pattern of interaction being the same when behavioral intentions was the dependent variable.

\section{Insert Figure 3 about here}

To break down the interaction, contrasts were performed comparing each entity at the different levels of social identity (SI). When SI with the home carrier was strong, contrasts indicated that customers were significantly more satisfied and displayed more favorable behavioral intentions towards the home carrier than either the partner airline or the alliance $(p<.001)$. In addition, there was a significant difference in ratings between the partner airline and the alliance, with the latter receiving significantly higher ratings than the former $(p<.001)$. When identification with the home carrier was weak, contrasts indicated that customers were significantly more satisfied with, and had more favorable intentions towards the home carrier than the partner airline $(p<.01)$. There was also a significant difference in ratings on both dependent variables between the partner airline and the alliance at the .05 level, with the latter being rated significantly higher than the former. There was no significant difference in ratings for satisfaction and behavioral intentions for the home carrier and the alliance $(p>.05)$.

Simple effects tests undertaken within each entity evaluation revealed that when the home carrier was evaluated, subjects gave significantly higher ratings for both satisfaction and behavioral intentions if they strongly identified with the home carrier than if they weakly identified. There was also a significant difference for ratings of the alliance whereby customers who strongly identified with the home carrier reported significantly higher satisfaction and behavioral intention ratings than if they weakly identified with the home carrier. There was no significant difference in ratings on satisfaction $(p>.05)$ and behavioral intentions $(p>.05)$ for the partner airline in regard to the strength of identification with the home carrier.

In general, an inspection of the graph (Figure 3) suggests that consumers who identify strongly with an airline tend to judge the outsider (partner) more harshly than those who do not identify with an airline. In summary, Hypotheses 2.1 was supported; Hypothesis 2.2 received partial support as even when identification with the home carrier was weak a significant difference in ratings for the three entities was evident, with the home carrier and the alliance being rated significantly higher than the partner airline. 


\section{DISCUSSION}

\section{Locus of Service Failure}

Results from this study provided insights into the effects of attributions for a service failure that to date have not been investigated. Previous studies have focused on the direct effect of a service provider causing and also dealing with the service failure, and subsequent consumer evaluations and behavior (e.g., Sparks \& Callan, 1996; Swanson \& Kelley, 2001). Results of these studies indicated that in evaluating recovery outcomes consumers identify potential causes and the party's responsibility for the resolution of the failure. Effects investigated in the current study resulted from the unique situation that in a strategic alliance setting the service provider that causes the service failure may not be the service provider that has to deal with it in the providercustomer interface. Thus, consumers' evaluation of the airline that caused the service failure may to a certain extent be affected by their evaluation of the airline that dealt with the service failure.

Hypothesis $\mathrm{H}_{1}$ was only partially supported, as the airline that caused the service failure did not always receive the most negative consumer evaluations and behavior. In particular, when the home carrier caused the service failure, it still received the highest satisfaction and behavioral intention ratings, followed by the alliance and then the partner airline. In contrast, when the partner airline caused the service failure, it experienced the greatest negative impact, as predicted, followed by the alliance rather than the home carrier.

Thus, the greatest variation in impact on satisfaction and behavioral intentions, based on the locus of service failure, is experienced by the partner airline. Respondents more readily related the service failure to that particular airline. This result may be explained with reference to the relationship marketing literature (Morgan \& Hunt, 1994). The link between strong, long-term relationships and beneficial outcomes for the organization is well established (Morgan \& Hunt, 1994; Reichheld \& Sasser, 1990). Conversely, if consumers are not familiar with and/or do not have a relationship with a particular airline, as for example, with an alliance partner airline, then more negative consequences from a service failure can be expected. However, consumer evaluations and behavior for the partner airline were still unexpectedly high when it dealt with a service failure that was caused by another airline. It appears that consumers' perception of the way the service failure was handled/recovered by the partner airline contributed to the relatively high ratings. Thus, the consequences of involvement in a service failure situation were less severe when the partner airline - which did not cause the service failure - did have an opportunity to interact with the customer and implement a successful service recovery. At the same time, it may also be in part due to the previous relationship and consequent goodwill a consumer may have 
had towards the airline that caused the service failure so that there is a certain transfer of goodwill towards the partner airline. In stark contrast, the service failure caused by the partner airline results in the expected negative impacts on satisfaction and behavioral intention ratings due to the lack of familiarity/relationship that could have mitigated the impact of a service failure. Indeed, the consequences may have been even more pronounced since the partner airline did not have an opportunity to recover from the service failure it had caused, with another airline implementing a successful service recovery, so that the partner airline is associated in the consumer's mind only with the service failure it caused but not with its recovery. Thus, the partner airline received the lowest ratings on both dependent variables, consistent with attribution theory (Weiner, 1985b).

In contrast, for the home carrier, the impact of familiarity and a previous relationship with that airline together with perceptions of a superior service recovery when it deals with the service failure seemingly account for the fact that there were no significant differences in ratings, regardless whether it or the partner airline caused the service failure. Behavioral intentions were still the highest for the home carrier, relative to the partner airline and the alliance. The latter finding may in part also be due to switching barriers such as schedule convenience and loss of frequent flyer benefits, consistent with findings in previous studies (e.g., Proussaloglou \& Koppelman, 1999). However, another reason may be that as it is the home carrier, people recall their previous positive experience with that carrier, and therefore, regard this particular service failure event as an isolated incident. Thus, more global consumer evaluations and behavior are not greatly affected. However, in this study, stability, one dimension of attribution, has purposely not been investigated, given the initial study objectives. However, future research may investigate the impact of multiple service failure events, and exactly at what time global evaluations of a service provider such as an airline and consequent consumer behavior are negatively affected. Maxham and Netemayer (2002) already shed some light on the effects of multiple service failures and recovery attempts. However, that study also focused on a single service provider only, in addition to the number of service failures/recoveries being confined to two.

In brief, results indicate that a previous relationship with an airline mitigates the impact of the service failure event in a strategic alliance setting, and thereby mitigates the suggested effect based on attribution theory (Weiner, 1985a) that if the cause can be attributed to a particular entity, consumer responses to that entity should be negatively affected. Previous study results based on attribution theory typically have not taken the effect of previous experience and past satisfaction into account but have tended to adopt a service encounter focus (e.g., Swanson \& Kelley, 2001). 
The impact on the alliance under both 'locus of service failure' conditions was also of interest. When the home carrier caused the service failure and the partner airline dealt with it, the alliance received considerably higher satisfaction and behavioral intention ratings than the partner airline (ratings were even more pronounced when the partner airline caused the service failure). This may in part be due to consumers' relationship with the home carrier and the continued desire to use this airline in the future. However, rather than involve the particular partner airline in the itinerary, consumers may choose another airline in the alliance, thus highlighting the need to assess switching behavior between partner airlines within an alliance. Again, this is an area of research that has received attention in a single service provider context only (e.g., Keaveney, 1995; Mittal \& Lassar, 1998)

\section{Social Identity}

Results provided support for Hypothesis $\mathrm{H}_{2.1}$, whereby consumers who strongly identified with the home carrier were more positive in their evaluation of, and behavior towards, this airline following a service failure than consumers who did not identify with that airline. This finding is consistent with previous research that highlighted the positive effects of identification with a particular organization (Ahearne, Battacharya, \& Gruen, 2005; Haslam et al., 2003). There was also evidence of a significant social identification-based difference in the evaluations by consumers of all three entities, lending partial support to Hypothesis $\mathrm{H}_{2.2}$.

In the present study, the service failure event was related to a computer breakdown that was perceived as beyond the control of the airline that dealt with the service failure. Nevertheless, the strong affiliation with the home carrier prevailed, resulting in more positive evaluations for the home carrier than those of weak identifiers. However, that was not the case for the partner airline for which there was no significant difference in evaluation between the strong and weak identifiers. In other words, the goodwill that the home carrier enjoys due to a consumer's strength of identification does not appear to translate into goodwill for the home carrier's partner airlines in an alliance.

Compared to weak identifiers, strong identifiers were not only more positive in their evaluation of the home carrier but also in their evaluation of the alliance. Thus, there appears to be a moderate halo effect (Thorndike, 1920), whereby positive evaluations of the home carrier are transferred to the alliance. Halo effects have long been discussed in the marketing literature, referring to distortions of consumer perceptions of attribute-specific properties of goods and services (e.g., Beckwith, Kassarjian \& Lehmann, 1978; Nisbett \& Wilson, 1977), in an attempt to 
maintain cognitive consistency (Abelson, et al., 1968). More recently, Wirtz and Bateson (1995) discussed halo effects relating to satisfaction measures of service attributes, while Halstead, Morash and Ozment (1996) examined halo effects in the context of complaint behavior. In this case, however, there appears to be a transfer from one service provider to a separate yet related entity, going even beyond the inferences made from a single employee of a service provider to other employees within that firm (Folkes \& Patrick, 2003).

These results also appear to lend further support to previous study findings that suggest that consumers do not have specific expectations about the role of an alliance entity in a service failure/recovery situation (Weber, 2005), and thus, may benefit from association with a brand a consumer identifies with. This is in stark contrast to an airline, specifically the partner airline with which consumers do not have an affiliation, but appear to have very clear expectations for a service recovery and rate it very negatively, if these expectations are not met.

Several managerial implications emerge. In order to strengthen relationships with their customers, especially the most frequent and profitable ones, it is essential for alliance airlines to be concerned not only about their own service standards and policies relating to service failure events and recovery but to be also mindful of those of their partner airlines. In the first instance, this concern would translate into readily offering solutions to a customer who has communicated a service failure event by one of the partner airlines. Clearly, having spent time to relating such an incident to the airline s/he is loyal to means that the expectations are higher than simply receiving a standard reply without acceptance of any responsibility.

In addition, in soliciting feedback from their customers, airlines may need to ascertain customer experiences on flights operated by partner airlines via a code-share agreement with the express purpose of offering remedial action in case of service problems. Such action would indicate to the customer that the airline not only has an understanding of the complexity of the relationships in an alliance setting but also that it is proactive in ensuring that the experience of its valued customers is of a standard they expect. As a potential means of conflict resolution, alliances may want to consider an alliance customer service center rather than leaving its customers alone in dealing with the various alliance partners.

Findings of this research also pointed to the fact that a consumer's identification with a particular airline has the potential to lessen the impact of a service failure event, if that service failure is caused by an alliance partner airline. However, for such positive effects to eventuate, 
that airline has to ensure that its dealings with the customer clearly indicate the airline's appreciation of that customer's use of the airline. In other words, implemented procedures and actions taken have to communicate to the customer that $\mathrm{s} /$ he is a valued customer.

\section{LIMITATIONS AND FUTURE RESEARCH}

First, this research involved an experiment, with respondents being randomly assigned to treatment conditions. Therefore, results have a high degree of internal validity (Cook \& Campbell, 1979). However, threats to the internal validity resulting from carry-over effects due to the use of a within-subject design were a possibility. These threats, however, were reduced by randomizing the ordering of scenario scripts between subjects.

The use of hypothetical service failure scenarios is a second limitation of this research as it is difficult to simulate the cognitive and emotional involvement generated by an actual service failure/recovery event. However, extensive pre-testing of the stimulus material, and subsequent checks on the realism and identification with the role of the customer, indicated a high degree of involvement of respondents.

The response rate of 6.3\% was low and precludes any attempt at drawing conclusions to the broader population of frequent flyers. Further research using alternative methods to test the hypotheses is warranted. Studies aiming to generalize findings need to carefully consider potential response rates, and thus, that may preclude the use of lists from certain list brokers that allow list members to just click the start of the survey to obtain the incentive/reward money rather than trying to complete the survey.

The findings of the present research offer several avenues for further exploration, specifically the assessment of 1) the impact of different types of service failures; 2) the impact of service failures with varying levels of severity, and 3) the effect of repeated service failure events, as opposed to a single one, that are potentially indicative of structural problems on the evaluation of various alliance entities. Study findings may also be validated in settings other than the strategic airline alliance setting used in this study. For example, it may be of interest whether the findings of this research are applicable only to horizontal alliances; that is, alliances that bring together service providers offering the same service product to the consumer, such as air travel, or whether they are equally applicable in vertical alliances; that is, alliances that bring together service providers offering different service products, such as air travel and hotels. Similarly, future research may also assess whether the current findings extend to more loosely integrated 
service networks (e.g., Smith \& Tax, 2005). Indeed, investigating the impact of a service failure event caused by a single service provider on a tourist's experience in a destination, and its effect on a tourist's perception of other service providers and the destination brand may also present a fruitful avenue for further research.

Finally, future research could assess whether the findings transfer to consumers with different cultural backgrounds. Some studies have noted cultural differences in consumer evaluations and behavior resulting from service failure events (e.g., Lee \& Sparks, 2007; Watkins \& Liu 1996). Thus, it is conceivable that such differences in cultural background also affect consumer responses to a service failure event in multiple service provider settings. In particular, the impact of social identity may vary between consumers of different cultural backgrounds, with status and recognition being afforded varying importance in different cultures. 


\section{REFERENCES}

Abelson, R.P., Aronson, E., Mc Guire, W.J., Newcomb, T.M., Rosenberg, M.J. and Tannenbaum, P.H. (Eds) (1968), “Theories of Cognitive Consistency: A Sourcebook,” Rand McNally, Chicago, IL.

Achrol, Ravi S. and Philip Kotler (1999), “Marketing in the Network Economy,” Journal of Marketing, 63 (4), 146-63.

Ahearne, Michael, C.B. Bhattacharya, and Thomas Gruen (2005), “Antecedents and Consequences of Customer-Company Identification: Expanding the Scope of Relationship Marketing,” Journal of Applied Psychology, 90 (3), 574-585.

Ahluwalia, Rohini, Robert E. Burnkrant, and H. Rao Unnava (2000), “Consumer Responses to Negative Publicity: The Moderating Role of Commitment,” Journal of Marketing Research, 37 (May), 203-214.

Becker, Cherylynn. (2000). Service Recovery Strategies: The Impact of Cultural Differences Journal of Hospitality \& Tourism Research, 24 (4): 526 - 538.

Beckwith, N.E., Kassarjian, H.H. and Lehmann, D.R. (1978), "Halo effects in marketing research: review and prognosis”, in Hunt, H.K. (Ed.), Advances in Consumer Research, Vol. 5, Association for Consumer Research, Ann Arbor, MI, pp. 465-67.

Bejou, David., Edvardsson, Bo and Rakowski, James.P. (1996). Critical Incident Approach to examining the Effects of Service Failures on Customer Relationships: The Case of Swedish and U.S. Airlines. Journal of Travel Research, 35: 35 - 40.

Bhattacharya, C.B., Hayagreeva Rao, and Mary Ann Glynn (1995), "Understanding the Bond of Identification: An Investigation of its Correlates Among Art Museum Members,” Journal of Marketing, 59 (4), 46-57.

Bhattacharya, C.B. and Sankar Sen (2003), “Consumer-Company Identification: A Framework for Understanding Consumers’ Relationships with Companies,” Journal of Marketing, 67 (2), 76-88.

Bitner, Mary J. and Amy R. Hubbert (1994), “Encounter Satisfaction Versus Overall Satisfaction Versus Quality: The Customer's Voice. In Service Quality: New Directions in Theory and Practice, Roland T. Rust and Richard. L. Oliver, eds. Thousand Oaks, CA: Sage Publication, 72-94.

Black, Hulda G. and Kelley, Scott W. (2009). A storytelling perspective on online customer reviews reporting service failure and recovery. Journal of Travel \& Tourism Marketing, 26 (2): $169-179$. 
Boshoff, Christo and Jason Leong (1998). "Empowerment, Attribution and Apologizing as Dimensions of Service Recovery: An Experimental Study,” International Journal of Service Industry Management, 9 (1): 24-47.

Bowen, Brent and Dean E. Headley (2005), “2005 Airline Quality Rating,” Omaha: University of Nebraska.

Bradley, Graham. L. and Sparks, Beverley A. (2009). Dealing with service failures: the use of explanations Journal of Travel \& Tourism Marketing, 26 (2): 129 - 143.

Chan, Haksin, Wan, Lisa C., and Sin, Leo Y.M (2007). Hospitality service failures: Who will be more dissatisfied? International Journal of Hospitality Management, 26 (3): 531-545.

Chang, J.C. (2008). “Tourists' Satisfaction Judgments: An Investigation of Emotion, Equity, and Attribution,” Journal of Hospitality \& Tourism Management, 32 (1): 108-134.

Choi, Summee and Anna S. Mattila (2008), "Perceived Controllability and Service Expectations: Influences on Customer Reactions Following Service Failure”, Journal of Business Research, 61, 24-30.

Colenutt, Christina E, and Ronald E. McCarville. (1994). The client as problem solver: A new look at service recovery. Journal of Hospitality \& Leisure Marketing 2 (3):23-35.

Collie, Therese A., B. A. Sparks, and G. L. Bradley. (2000). Investing in interactional justice: A study of the fair process effect within a hospitality failure context. Journal of Hospitality \&Tourism Research 24 (4):448-472.

Cook, Thomas D. and Donald T. Campbell (1979). Quasi-experimentation: Design \& Analysis Issues for Field Settings. Boston: Houghton Mifflin Company.

Cranage, David A., and Sujan, Harish. (2004). Customer choice: A pre-emptive strategy to buffer the effects of service failure and improve customer loyalty. Journal of Hospitality and Tourism Research, 28(1): 3-20.

Dutton, Jane E., Janet M. Dukerich, and Celia V. Harquail (1994), “Organizational Images and Member Identification,” Administrative Science Quarterly, 39 (2), 239-263.

Evans, Nigel. (2001). "Collaborative strategy: an analysis of the changing world of international airline alliances,” Tourism Management, 22 (3): 229-243.

Ferreira, Raymond (1996). "The effect of private club members’ characteristics on the identification level of members,” Journal of Hospitality \& Leisure Marketing, 4 (3): $41-62$

Folkes, Valerie S. and Vanessa M. Patrick (2003), “The Positivity Effect of Perceptions of Services: Seen One, Seen Them All?” Journal of Consumer Research, 30 (1), 125-137.

Gittell, Jody H. (2002), “Relationships Between Service Providers and Their Impact on. Customers,” Journal of Service Research, 4 (4), 299-311. 
Goh, Kevin, and Mark Uncles. (2003). "The Benefits of Airline Global Alliances: An Empirical Assessment of the Perceptions of Business Travelers." Transportation Research A 37 (6): 479-497.

Ha, Jooyeon and Jang, Shawn. (2009). Perceived justice in service recovery and behavioral intentions: The role of relationship quality. International Journal of Hospitality Management, 28 (3): 319-327.

Halstead Diane, Edward A. Morash and John Ozment (1996). "Comparing objective service failures and subjective complaints : An investigation of domino and halo effects," Journal of Business Research, 36 (2):107-115

Haslam, S. Alexander, Nyla R. Branscombe, and Sebastian Bachmann (2003), "Why Consumers Rebel: Social Identity and the Etiology of Adverse Reactions to Service Failure,” In Social Identity at Work: Developing Theory for Organizational Practice, S. Alexander Haslam, D. v. Knippenberg, Michael J. Platow, and Naomi Ellemers, eds. New York: Psychology Press, 293-309.

Hoffman, K. Douglas and Beth G. Chung. (1999). Hospitality recovery strategies: Customer preference versus firm use. Journal of Hospitality \& Tourism Research 23 (1):71-84. Hogg, Michael A. and Dominic Abrams (1988), “Social Identifications: A Social Psychology of Intergroup Relations and Group Processes,” London: Routledge.

Iacobucci , Dawn. (1995) . The analysis of variance for unbalanced data. In David W. Stewart \& Naufel J. Vilcassim (Eds.), Marketing theory and applications (Vol. 6, pp. 337-343). Chicago: American Marketing Association.

Kelley, Scott W., K. Douglas Hoffman, and Mark A. Davis (1993), “A Typology of Retail Failures and Recoveries,” Journal of Retailing, 69 (4), 429-52.

Kramer, Roderick M. (1991), "Intergroup Relations and Organizational Dilemmas: The Role of Categorization Processes,” Research in Organizational Behavior, 13, 191-207.

Lee, Y.L. \& Beverley Sparks (2007). “Appraising Tourism and Hospitality Service Failure Events: A Chinese Perspective”. Journal of Hospitality \& Tourism Research, 31 (4): 504-529.

Lee, Kyuho, Khan, Mahmood A. and Ko, Jae-Youn (2008). A Cross-National Comparison of Consumer Perceptions of Service Recovery. Journal of Travel \& Tourism Marketing, 24 (1): $1-16$

Little, Roderick J. A., \& Rubin, Donald B. (1987). Statistical analysis with missing data. New York: Wiley. 
Karatepe, Osman M. (2006). Customer complaints and organizational responses: the effects of complainants' perceptions of justice on satisfaction and loyalty. International Journal of Hospitality Management, 25 (1): 69-90.

Kim, Terry, Kim, Woo Gon and Kim, Hong-Bumm (2009). The effects of perceived justice on recovery satisfaction, trust, word-of-mouth, and revisit intention in upscale hotels. Tourism Management, 30 (1):51-62.

Mael, Fred and Blake E. Ashforth (1992), “Alumni and Their Alma Mater: A Partial Test of the Reformulated Model of Organizational Identification,” Journal of Organizational Behavior, 13 (2), 103-23.

Mattila, Anna S. (1999). An examination of factors affecting service recovery in a restaurant setting. Journal of Hospitality \& Tourism Research 23 (3):284-298.

Mattila, Anna, S. (2000). The impact of culture and gender on customer evaluations of service encounters. Journal of Hospitality \& Tourism Research. 24(2), 263-273.

Mattila, Anna S. (2001), “The Impact of Relationship Type on Customer Loyalty in a Context of Service Failures,” Journal of Service Research, 4 (2), 91-101.

Mattila, Anna S., Cho, Wonae. and Ro, Heejung. (2009). The Joint Effects of Service Failure Mode, Recovery Effort and Gender on Customers’ Post-recovery Satisfaction, Journal of Travel \& Tourism Marketing: 26 (2): 120-128.

Maxham, James, G. and Richard G. Netemeyer (2002). "A Longitudinal Study of Complaining Customers' Evaluations of Multiple Service Failures and Recovery Efforts," Journal of Marketing, 66 (4): 57-71.

McCollough, Michael A. (2000). The effect of perceived justice and attributions regarding service failure and recovery on post-recovery customer satisfaction and service quality attitudes. Journal of Hospitality \& Tourism Research 24 (4):423-447.

McDougall, Gordon H.G., and Terrence J. Levesque. (1998). The effectiveness of recovery strategies after service failure: An experiment in the hospitality industry. Journal of Hospitality \& Leisure Marketing 5 (2/3):27-49.

McDougall, Gordon H.G., and Terrence J. Levesque. (1999). Waiting for service: the effectiveness of recovery strategies. International Journal of Contemporary Hospitality Management 11 (1):6-15.

Mittal, Banwari and Walfried M. Lassar (1998). "Why do customers switch? The dynamics of satisfaction versus loyalty,” Journal of Services Marketing, 12 (3): 177 - 194

Morgan, Robert M. and Shelby D. Hunt (1994), “The Commitment-Trust Theory of Relationship Marketing,” Journal of Marketing, 58 (3), 20-38. 
Namkung, Young and Jang, Shawn (2009). The effects of interactional fairness on satisfaction and behavioral intentions: Mature versus non-mature customers. International Journal of Hospitality Management, 28 (3):397-405.

Nikolich, M.A., and Beverley A. Sparks. (1995). The hospitality service encounter: The role of communication. Hospitality Research Journal 19 (2):43-56.

Nisbett, Richard E.; Timothy D. Wilson (1977). "The halo effect: Evidence for unconscious alteration of judgments". Journal of Personality and Social Psychology (American Psychological Association) 35 (4): 250-256

Nunnally, J. C. (1978). Psychometric theory ( ${ }^{\text {nd }}$ ed.). New York: McGraw-Hill.

Patzer, Gordon L. (1996). Experiment-research methodology in marketing: types and applications. Quorum Books. Westport, CN.

Preble, John F., Reichel, Arie, \& Hoffman, Richard C. (2000). "Strategic alliances for competitive advantage: Evidence from Israel's hospitality and tourism industry.” International Journal of Hospitality Management, 19(3), 327-341.

Prenkert, Frans and Lars Hallén (2006), “Conceptualizing, delineating and analyzing business networks,” European Journal of Marketing, 40 (3/4), 384-407.

Proussaloglou, Kimon and Frank S. Koppelman (1999), “The Choice of Air Carrier, Flight, and Fare Class,” Journal of Air Transport Management, 5 (4), 193-201.

Reichheld, Frederick F., and W. Earl Sasser (1990), “Zero Defections: Quality Comes to Services,” Harvard Business Review, 68 (5), 105-11.

Sawyer, Alan G. and Ball, A. Dwayne. (1981). Statistical Power and Effect Size in Marketing Research. Journal of Marketing Research 18 (3): 275-290.

Scott, Susanne G. and Vicky R. Lane (2000), “A Stakeholder Approach to Organizational Identity,” The Academy of Management Review, 25 (1), 43-62.

Searle, Shayle. (1987). Linear models for unbalanced data. New York: Wiley.

Skytrax (2009) - www.skytrax.com

Smith, Amy K. and Stephen S. Tax (2005), “A Pound of Flesh, But From Whom? Assessing Failure \& Recovery in a Service Network,” Paper presented at the 2005 SERVSIG Conference Singapore.

Sparks, Beverley A. (2001). Managing service failure through recovery. In Service quality management in hospitality, tourism, and leisure, edited by J. Kandampully, C. Mok and B. Sparks. New York: Haworth Press. 193-221.

Sparks, Beverley A. (2002). I would have felt better if only...Or, how to enhance customer satisfaction after service problems. Journal of Quality Assurance in Hospitality and Tourism 3 (1/2):53-67. 
Sparks, Beverley A., and Graham L. Bradley (1997). Antecedents and consequences of perceived service provider effort in the hospitality industry. Hospitality Research Journal 20 (3):1734.

Sparks, Beverley A and Fredline, Liz (2007). Providing an Explanation for Service Failure: Context, Content, and Customer Responses. Journal of Hospitality \& Tourism Research, 31 (May): 241 - 260.

Sparks, Beverley A., and Victor J. Callan. (1996). Service breakdowns and service evaluations: The role of customer attributions. Journal of Hospitality \& Leisure Marketing 4 (2):3-23. Susskind, Alex. M. (2005). “A Content Analysis of Consumer Complaints, Remedies, and Repatronage Intentions Regarding Dissatisfying Service Experiences,” Journal of Hospitality \& Tourism Research, 29 (2): 150-169.

Swanson, Scott. R. and Scott W. Kelley (2001), "Service Recovery Attributions and Word-ofMouth Intentions,” European Journal of Marketing, 35 (1/2), 194-211.

Sultan, Fareena and Merlin C. Simpson (2000). "International service variants: airline passenger expectations and perceptions of service quality," Journal of Service Marketing, 14 (3): 188-216.

Sundaram, D.S., Claudia Jurowski, and Cynthia Webster. (1997). Service failure recovery efforts in restaurant dining. Hospitality Research Journal 20 (3):137-49.

Tajfel, Henri and John. C. Turner (1985). "The Social Identity Theory of Group Behavior.” In Psychology of Intergroup Relations. Vol. 2. Steven Worchel and William G. Austin, eds. Chicago: Nelson-Hall, 7-24.

Thorndike, E. L. (1920). "A constant error on psychological rating". Journal of Applied Psychology, IV, 25-29

Van, Knippenberg, Daan and Els C.M. van Schie (2000). " Foci and correlates of organizational identification," Journal of Occupational and Organizational Psychology, 73 (2): 137-147.

Vargo, Stephen L. and Robert F. Lusch (2004), "Evolving to a New Dominant Logic in Services Marketing,” Journal of Marketing, 68 (1), 1-17.

Wang, Chen-ya, Mattila, Anna S. and Bartlett, Albert (2009). An examination of explanation typology on perceived informational fairness in the context of air travel. Journal of Travel \& Tourism Marketing, 26 (8): 795 - 805.

Watkins, Harry S. and Raymond Liu (1996), “Collectivism, Individualism and In-Group Membership: Implications for Consumer Complaining Behaviors in Multicultural Contexts,” Journal of International Consumer Marketing, 8 (3/4), 69-96. 
Weber, Karin (2002), “Consumer Perceptions and Behavior: Neglected Dimensions in Research on Strategic Airline Alliances,” Journal of Travel \& Tourism Marketing, 13 (4), 27-46.

Weber, Karin (2005), “Travelers' Perceptions of Airline Alliance Benefits and Performance”. Journal of Travel Research, 43 (3): 257-265.

Weiner, Bernard (1980), “Human Motivation,” New York: Holt, Rinehart, and Winston.

Weiner, Bernard (1985a), “An Attributional Theory of Achievement-Related Emotion and Motivation,” Psychological Review, 92 (4), 548-73.

Weiner, Bernard (1985b), “Spontaneous Causal Thinking,” Psychological Bulletin, 97 (1): 74-84.

Westbrock, Richard A. and Richard L. Oliver (1991), “The Dimensions of Consumption Emotion Patterns and Consumer Satisfaction,” Journal of Consumer Research, 18 (1), 84-91.

Whyte, Randall (2002), “Loyalty Marketing and Frequent Flyer Programmes: Attitudes and Attributes of Corporate Travellers,” Journal of Vacation Marketing, 9 (1), 17-34.

Wilson, Pamela and McNamara, J. Regis (1982), "How Perceptions of a Simulated PhysicianPatient Interaction Influence Intended Satisfaction and Compliance,” Social Science and Medicine, 16 (19), 1699-1704.

Wirtz, Jochen. and Bateson, John .E.G. (1995), An experimental investigation of halo effects in satisfaction measures of service attributes." International Journal of Service Industry Management, 6 (3): 84-102.

Wirtz, Jochen and Robert Johnston (2003), "Singapore Airlines: what it takes to sustain service excellence - a senior management perspective", Managing Service Quality, 13 (1): 10-19.

Zeithaml, Valerie. A., Leonard. L. Berry, and A. Parasuraman (1996), “The Behavioral Consequences of Service Quality,” Journal of Marketing, 60 (2), 31-46. 
Table 1

Summary of Significant MANOVA Results

\begin{tabular}{|c|c|c|c|c|c|c|}
\hline \multirow[b]{2}{*}{ Source } & \multicolumn{3}{|c|}{ Multivariate } & \multicolumn{3}{|c|}{ Univariate } \\
\hline & $\boldsymbol{F}$ & $p$ & $\eta_{p}^{2}$ & $F$ & $p$ & $\eta_{p}^{2}$ \\
\hline
\end{tabular}

MAIN EFFECTS

Locus of Service Failure

$\begin{array}{lll}3.08 & .048 & .023\end{array}$

Satisfaction

$5.28 \quad .022 * \quad .020$

Behavioral Intentions

$5.95 \quad .015^{*} \quad .022$

Social Identity

$\begin{array}{lll}14.39 & .000 & .100\end{array}$

Satisfaction

$25.60 \quad .000 * \quad .090$

Behavioral Intentions

$27.19 .000 * \quad .095$

Entity

$\begin{array}{lll}21.12 & .000 & .248\end{array}$

Satisfaction

$41.35 \quad .000 * \quad .138$

Behavioral Intentions

$43.56 \quad .000 * \quad .144$

\section{INTERACTION EFFECTS}

$\begin{array}{llll}\text { Locus of Service Failure x Entity } & 12.33 & .000 & .161\end{array}$

Satisfaction

$23.83 .000 * \quad .084$

Behavioral Intentions

$25.58 .000 * \quad .090$

Social Identity x Entity

$\begin{array}{lll}8.66 & .000 & .119\end{array}$

Satisfaction

$4.56 \quad .011^{*} .017$

Behavioral Intentions

$19.05 .000 * \quad .069$

\footnotetext{
* Significant with the application of the Bonferroni correction $p<.025$
} 


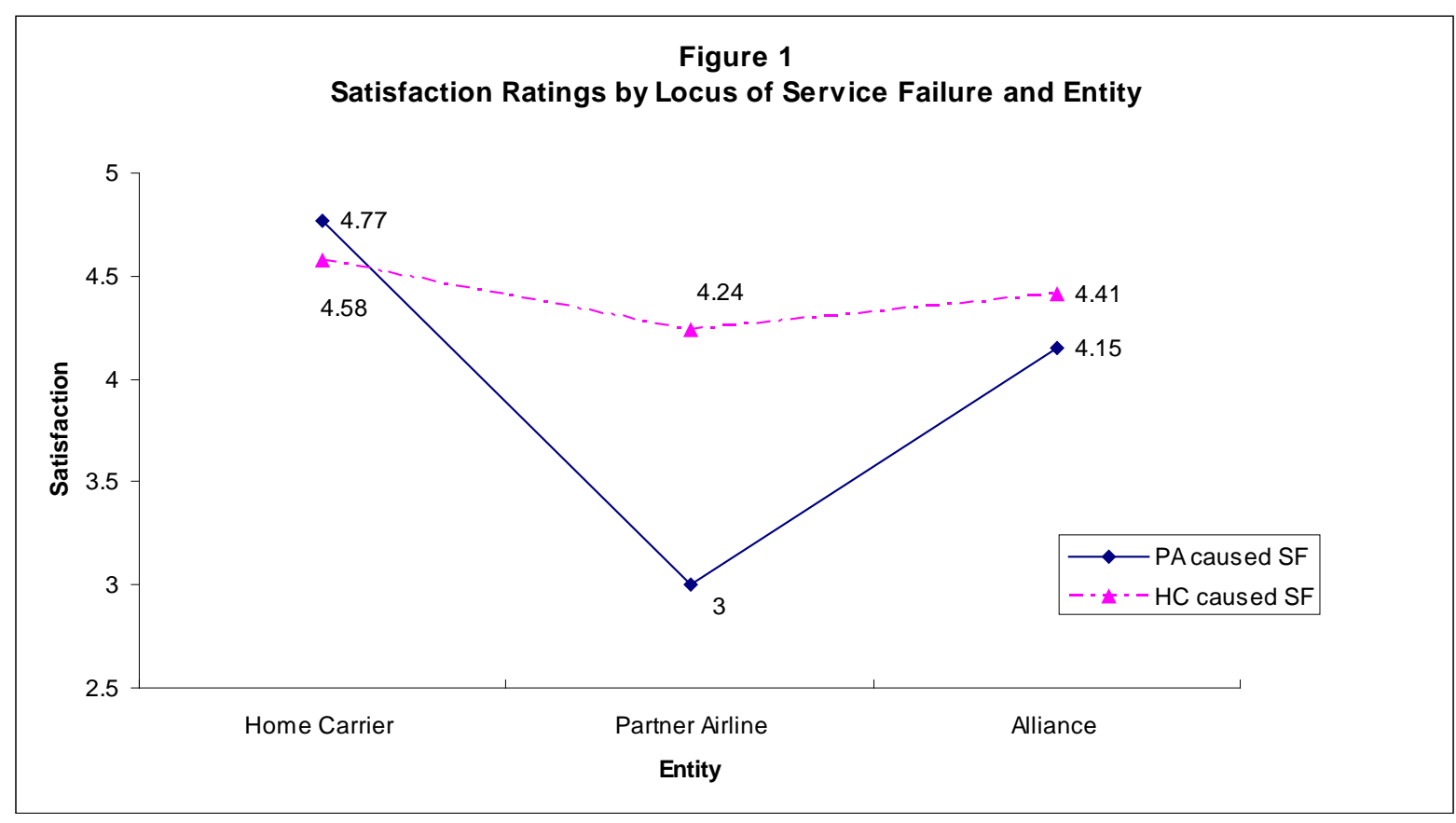


Figure 2

Behavorial Intention Ratings by Locus of Service Failure and Entity

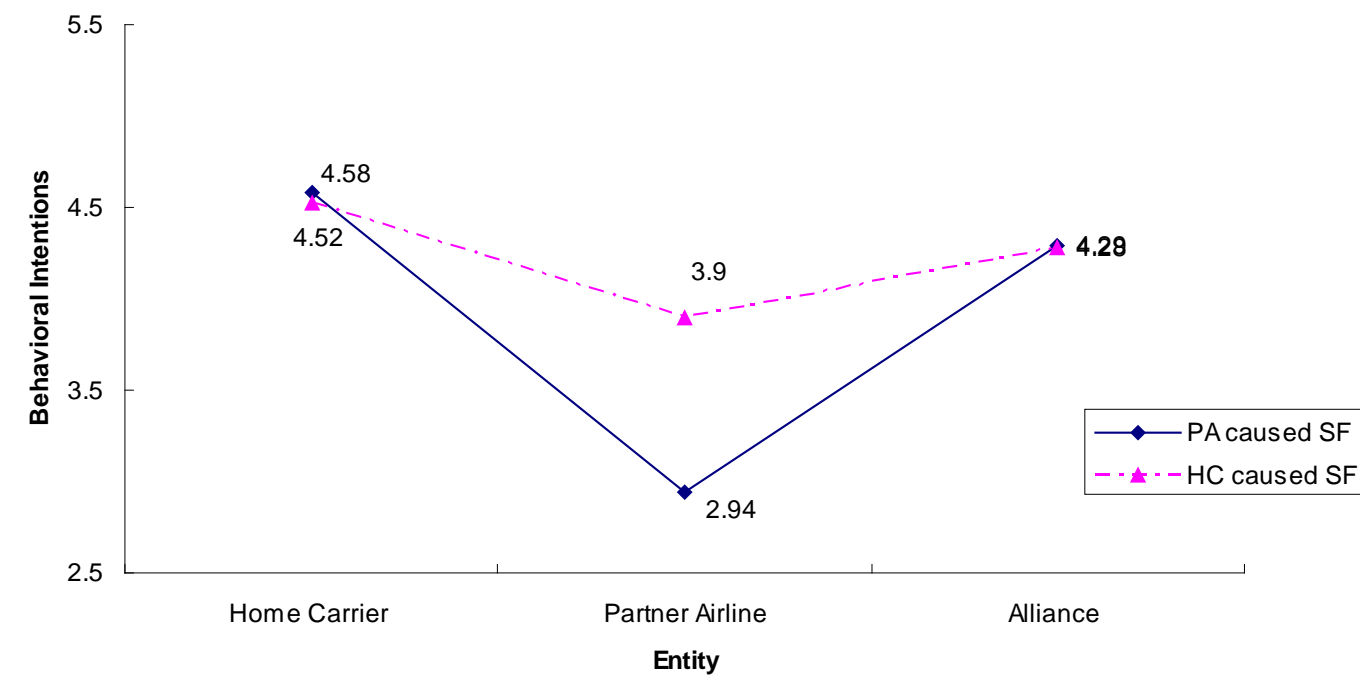


Figure 3

Satisfaction Ratings by Social Identity and Entity

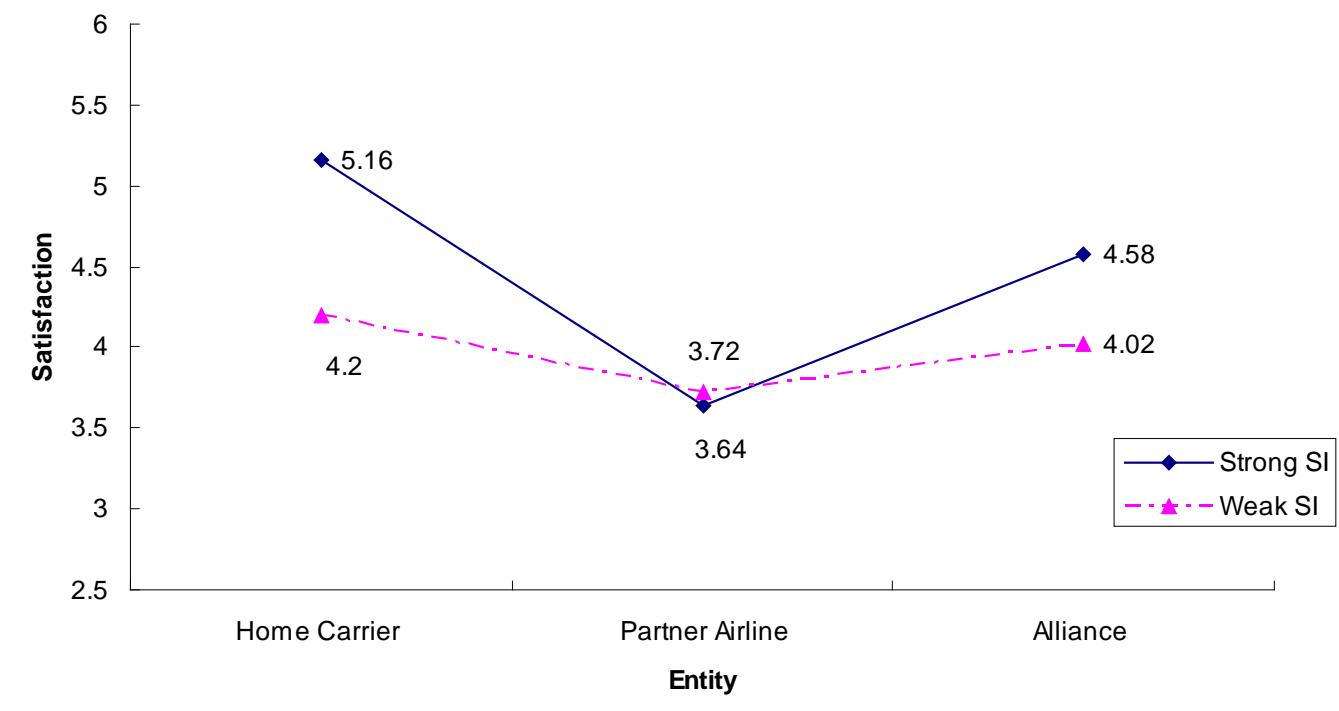




\section{APPENDIX A \\ Sample of Scenario with the Various Conditions}

\section{Note: All conditions contained this background information:}

The scenario you are about to read is concerned with the service of strategic airline alliances and its individual member airlines. The Star Alliance and Oneworld are the two major global strategic airline alliances.

The Star alliance consists of 15 member airlines - its partner airlines are Air Canada, Air New Zealand, All Nippon Airways, Asiana Airlines, Austrian Airlines, British Midland, LOT, Lufthansa, SAS, Singapore Airlines, Spanair, Thai Airways, United Airlines, US Airways and Varig.

The Oneworld Alliance consists of 8 member airlines - its partner airlines are Air Lingus, American Airlines, British Airways, Cathay Pacific, Finnair, Iberia, Lan Chile and Qantas.

\section{Strong identification}

We would like you to imagine that you have a strong affiliation with a particular Airline and we will call this airline your 'home carrier - Airline ABC' - so imagine a situation where you fly a lot, especially internationally, using your 'home carrier - Airline ABC'. You strongly believe in what your airline stands for, the leadership it has taken in the airline industry with innovative ideas and its resilience to withstand difficult times. The airline enjoys a reputation of excellence and customer orientation, and you feel very proud to be associated with such an airline. You often praise the airline and recommend it to your friends and colleagues. When you fly with the airline you feel good about yourself.

The following scenario describes a service interaction. Please read the scenario carefully and remember your strong affiliation with your 'home carrier - Airline ABC'.

\section{Weak identification}

We would like you to imagine that you fly a lot, especially internationally. You typically travel with a number of different airlines, with price and schedule convenience being your main selection criteria in choosing an airline for a particular trip. As far as you are concerned, the airlines you travel with are all very similar in the level of service they provide and as a result you don't have a strong affiliation with any one of those airlines. Therefore, when friends or colleagues ask for a recommendation of an airline you provide an account of the positive and negative aspects of each airline you use rather than recommending a single airline.

The following scenario describes a service interaction. Please read the scenario carefully.

You are booked in business class on an international flight that involves several flight sectors and will take you to numerous destinations over a three-week period. The flight is serviced by two airlines: [Strong identification includes additional text: your home carrier] Airline ABC and its Partner Airline XYZ - both airlines are members of one of the global airline alliances that frequently emphasize seamless travel and greater convenience for its passengers in its promotion. You usually book and travel with [Strong identification includes additional text: your home carrier] Airline ABC. However, since you are traveling with business colleagues as part of a 
delegation, an office other than your own has organized the trip details so that both [Strong identification includes additional text: your home carrier] Airline ABC and Partner Airline XYZ service and operate the various flight sectors.

\section{Partner Airline causes failure ${ }^{1}$}

Everything goes smoothly for the flights in the first week of travel. However, when you arrive at the airport to check in for your next flight, operated by Partner Airline XYZ, there are long lines at the check-in counters and you learn that there has been a breakdown of Partner Airline XYZ's main computer system so that all their passengers need to be checked in manually. You wait in line for about 20 minutes before stepping up to the checkin counter and being greeted by a staff member of Airline ABC - Airline ABC handles the ground arrangements, including the check-in, for Partner Airline $\mathrm{XYZ}$ on this occasion.

The staff member from [Strong identification includes additional text: your home carrier] Airline ABC explains: "Due to a breakdown of Partner Airline XYZ's main computer system, all earlier flights have been delayed due to the required manual check-in process.

\section{Home Airline causes failure ${ }^{1}$}

Everything goes smoothly for the flights in the first week of travel. However, when you arrive at the airport to check in for your next flight, operated by Airline $\mathrm{ABC}$, there are long lines at the check-in counters and you learn that there has been a breakdown of Airline ABC's main computer system so that all their passengers need to be checked in manually. You wait in line for about 20 minutes before stepping up to the checkin counter and being greeted by a staff member of Partner Airline XYZ - Partner Airline XYZ handles the ground arrangements, including the check-in, for Airline ABC on this occasion.

The staff member from Partner Airline XYZ explains: "Due to a breakdown of Airline ABC's main computer system, all earlier flights have been delayed due to the required manual check-in process.

The flight you were originally booked on this evening will also be affected by these delays - it won't leave until tomorrow morning due to the need to first clear the earlier flights and night flight restrictions that come into effect at $11.30 \mathrm{pm}$. As now all the earlier flights are completely full, unfortunately you will not be able to travel tonight.

Since you have to attend pre-scheduled meetings as part of the delegation the next morning you voice strong objections and urge the staff member of Airline ABC [Partner Airline XYZ] to find a way to accommodate you on a flight that evening. The staff member is very courteous throughout your interactions and tries very hard to resolve the problem. Yet, despite your confirmed ticket in the end you are the only member of your delegation who cannot get on a flight that evening - you are left with no other choice than to take a flight the next morning and therefore, miss part of the meetings of your delegation. The staff member of Airline ABC [Partner Airline XYZ] can only offer you several alternative flights by Partner Airline XYZ [Airline ABC] and other partner airlines the next morning, and asks for your preference. Then, as is standard airline policy the staff member provides you with free accommodation for the night and a meal and beverage voucher.

\footnotetext{
${ }^{1}$ The cause of the problem is always the airline that does NOT deal with the problem
} 
